\title{
EFL Politeness in Refusals by Students of Different Culture and Interlanguage Stages
}

\author{
Widya Wulandari ${ }^{1, *}$ Berlin Sibarani ${ }^{2}$, Anni Holila Pulungan ${ }^{3}$ \\ ${ }^{1}$ Postgraduate School, Universitas Negeri Medan, Jl. Willem Iskandar / Pasar V, Medan 20221, Indonesia \\ ${ }^{2}$ Postgraduate School, Universitas Negeri Medan, Jl. Willem Iskandar / Pasar V, Medan 20221, Indonesia \\ ${ }^{3}$ Postgraduate School, Universitas Negeri Medan, Jl. Willem Iskandar / Pasar V, Medan 20221, Indonesia \\ *Corresponding author. Email: wulandariwidya00@gmail.com
}

\begin{abstract}
This study deals with the EFL politeness in refusals by students of different culture and interlanguage stages. The objective of this research is to analyze how politeness in refusals are realized by the subjects of different culture and interlanguage stages. This study was a qualitative research. The data were taken from refusal expressions made by EFL Malay and Batak students with initial stage (stage 1-interlanguage) and free variation stage (stage-2 interlanguage). The data of this study were collected by using elicitation techniques by using Discourse Completion Task (DCT), pictures and Interview. The results of this study showed that the politeness in refusal among the Batak and Malay culture are both realized by direct and indirect strategy. The strategies used in both culture are followed by semantic formula, such as non performative statement, regret, reason, acceptance as refusal and future acceptance. The difference between the two realization of politeness in refusal is that the direct strategies are used more in Batak culture than those used in Malay culture. Semantic formula are used less in Batak culture than those in Malay culture.
\end{abstract}

Keywords: Politeness, Refusal, Culture, Interlanguage.

\section{INTRODUCTION}

Speakers and hearers must have intention not to be offended or need to be honored when doing communication. They do want to keep harmony. This kind of naturally intention relates to what term as politeness. Politeness is a way to polish the behavior, minimize conflict, keep cooperative interaction and smoothen the communication. Because of politeness has a great role and impact in communication, the language users or learners do need to be aware and understand about it. Politeness also exist in all kinds of speech act. Here the researcher is interesting in refusal which is a kind of initial respond of an act which has a great risk in threatening both the speaker and hearer face in communication. Since the goal of politeness is avoiding conflict, keeping cooperative principle and maintaining the mutual face so the researcher wonder how the English Foreign Language learner refuse something considering that goal of polite communication.

Politeness is inter-related to culture, what is regarded polite in one culture may not be the same among other cultures, the way to show politeness is also different among cultures. Every language community has a system of politeness, but the details associated with that system will vary since face is associated with the most essential cultural ideas concerning the nature of the social persona, honor, shame and thus to religious concepts [1].

In addition, discussing about English Foreign Language learner, it must also interrelated to interlanguage which is a linguistic stage or new language created by EFL learners. As interlanguage must be faced by the EFL learners when learn English as a target language, it is assumed that interlanguage stages may have the effect to EFL learners' way in producing politeness in English refusals because each EFL learner must have different interlanguage, so their ways to refuse are also varied. During the process of $\mathrm{L} 2$ learning, the learner create the interlanguage system derived from the learner's internal processing so that the learner's performance is variable and learners interlanguage keep changing until the target language system is fully shaped [2]. In regarding to the background above, this study aims to analyze how 
politeness in refusals are realized by the subjects of different culture and interlanguage stages.

\section{REVIEW OF LITERATURE}

\subsection{Definition of Politeness}

Politeness is defined as a system of interpersonal relations designed to facilitate interaction by minimizing the potential for conflict and confrontation inherent in all human interchanges [3]. Politeness have in common the elements of avoidance of conflicts and consideration of the hearer. Thus, we can assume that politeness involves speaker's intention not to offend the hearer in social interactions [4]. Politeness behavior is a polished behavior relying on social conventions, which are socially institutionalized and evaluated. Its main motivations are keeping a cooperative social interaction and avoiding unnecessary conflicts [5]. Politeness refers to the use of communication strategies intended to maintain mutual face and to achieve smooth communication, taking into account human relationships [6] . So, based on those expert definition it can be concluded that politeness is a way to polish the behavior, minimize conflict, keep cooperative interaction and smoothen the communication to reach the harmony between the speakers and hearers.

\subsection{Cultural Effect on Politeness}

Culture affect the understanding of politeness because of four parameters [7] ; social motivations, expressive modes, social differentials and social meanings. The four parameters significantly effect the social understanding of politeness across societies in the world. Social motivation is awareness for face concern which affects people to linguistically polite. It is individual striving to maintain face precerving interactional harmony. Expressive modes are all verbal and non verbal elements for communication. It is strategy for redressive action whether positive or negative politeness. Social meanings are attitudes or choices of linguistic encoding in particular situation or speech events. In other words, the degree to which any linguistic expression is deemed to be polite by members of a given culture in specific situations. Social differential is a term referring to such factors as social distance, power and the degree to which speech acts constitute an imposition on the addressee. They are, in other words, the D (social distance), $\mathrm{P}$ (power) and $\mathrm{R}$ (degree of imposition) factors.

\subsection{Refusal Strategies}

Refusals classified into two strategies, namely direct strategy and indirect strategy [8].
1. Direct strategies is directly refuse other people request. The direct refusals include ;

a) Performative (e.g., "I refuse")

b) Non performative statement ("no") or negative willingness / ability ("I can't!, I won't, I don't think so", etc.)

2. Indirect strategies is refusing other people request by saying it indirectly. The indirect refusals include;

a) Regret like "I'm sorry...." ; "I feel terrible ..."

b) Wish like "I wish I could help you..."

c) Excuse, reason, explanation like "I have an exam.", "My children will be home that night." "I have a headache."

d) Statement of alternative.

a. I can do X instead of Y (e.g., "I'd rather..."; "I'd prefer.")

b. Why don't you do $\mathrm{X}$ instead of $\mathrm{Y}$ (e.g., "Why don't you ask someone else?"

e) Future or past acceptance like "If I had enough money", "If you had asked me earlier", "I would have ..."

f) Promise of future acceptance like "I'll do it next time."

g) Statement of principle "I never drink right after dinner."; "I never do business with friends."

h) Statement of philosophy like "One can't be too careful."

i) Attempt to dissuade interlocutor

a. Threat or statement of negative consequences to the requester like "If I knew you would judge me like this I never did that" ; "I won't be any fun tonight"

b. Criticize the requester "It's a silly suggestion."

c. Guilt trip (e.g. waiter to customers who want to sit for a while "I can't make a living off people who just order tea")

d. Request for help, empathy, and assistance by dropping or holding the request.

e. Let interlocutor off the hook (e.g., "Don't worry about it." "That's okay." "You don't have to,")

f. Self-defense (e.g., "I'm trying my best." "I'm doing all I can do." "I do nothing wrong.")

g. Acceptance functioning as a refusal

h. Unspecific or indefinite reply "I don't know when I can give them to you"

i. Lack of enthusiasm "I'm not interested in diets"

j). Avoidance 
a. Non-verbal (silence, hesitation, doing nothing and physical departure)

b. Verbal (Topic switch, joke, repetition of part of request, etc. (e.g., "Monday?",

postponement (e.g., “I'll think about it."), hedging (e.g., "Gee, I don't know...." "I'm not sure....")

\subsection{Politeness in Refusals among Malay and Bataknese}

Bataknese are known as one of the tribes in Indonesia that have loud voice. They speak in directness or to the point and to chase the details to the core of the problem. Directness is the dominantly used by Bataknese because they do not like talk long-winded, if it is, they will say it. The Batak community does not use a social class-based speaking strategy because the Batak community is an egalitarian society. This is influenced by the traditional views about kinship system [9].

In Malay culture, the act of saying a straight 'no' as a refusal could be taken as an emotional offense to avoid embarrassing others, especially when the said person is someone with a high social status or the elderly. Malay society practices politeness by exercising indirect speech acts in daily conversation because Malays believe that by making an indirect speech act, the face between speakers can be preserved [10].

\subsection{Interlanguage Stages Effect on Politeness}

Interlanguage is the linguistic stage which second language learners go through during the process of mastering a target language [11]. Interlanguage is changing and called the process is a continuum and has the stages [12]. The stages start from the initial into the final, this stages based on the use of negation / negative sentences. Initial stage occurs when the simple forms used. Free variation occurs as when two (or more) forms are involved. The next stage (systematic variation) involves consistency of form/meaning relationships with overlapping forms and meanings. The final stage, categorical use stage (assuming that a learner reaches that point) is the correct form/meaning assignment.

Interlanguage stages are varied from one EFL students to others. This interlanguage are always changing, from native like (initial stage) into target like (categorical use stage). In each stages, the learners create their own rules of grammar and language performance. It means, students with different interlanguage stages produce different language performance. This process can also affect the expression made by the learners includes the politeness in refusal expressions. The student who are in native like stages will perform different with the students in target like stages.

\section{RESEARCH METHODOLOGY}

This study was conducted by applying descriptive qualitative design which data are collected in mostly words or pictures than numbers. In this research, case study was used.

The data of this study was the politeness in refusal expressions made by EFL students. The source of the data were the EFL students in the Junior High School (JHS) with different ethnic group (Malay and Batak) and interlanguage stages (stages 1 and 2). The Bataknese JHS students were taken from MTsN Tapanuli Utara while the Malay JHS students were taken from MTs Darul Hikmah Asahan. Those locations were selected because of the consideration of strong culture atmospheres. The number of the subjects to be involved in this study was taken by using snowball technique and the recurrent or saturation principles. The data of this study were collected by using elicitation techniques by using Discourse Completion Task (DCT), pictures and Interview. DCT is a data elicitation tool in which participants are expected to provide what would be a suitable answer to a given scenario [13]. In this research, the adapted written DCT [14 ]were used.

The subjects were asked to write the refusal based on the scenarios written in DCT. They were encouraged to respond spontaneously, and not thinking too much to their responses, then the responses from all the participants were collected as data for analyzing how the subjects form politeness in refusal. Then, they were asked to make the negative sentences based on the pictures to identify their stages. Interview were conducted by the researcher to get more data about the underlying reasons of subjects' refusal expressions. The answer of the interview were noted and recorded by using audio recorder.

In analyzing the data, the Interactive Model Technique [15] applied to analyze the data of this research. The analysis consist of three concurrent flows activities; data reduction, data display, and conclusion drawing/verification.

\section{RESULT AND DISCUSSION}

The results of the data analysis shows that politeness in refusal is realized in different ways depending on different interlanguage stages and culture. 


\subsection{The Realization of Politeness in Refusal based on the Subjects Interlanguage Stages}

Based on their interlanguage level, the subjects are divided into two classification, they are (a) the initial and (b) free-variation

\subsubsection{Realization of Politeness in Refusal by the Initial Interlanguage Stage Subjects}

The subjects with the initial stages realized politeness in refusal in three ways, they are: (1) indirect refusal by expressing regret + reasons, (2) direct refusal by expressing non performative statement + regret and (3) direct refusal by expressing regret + non performative statement + reasons. The results are supported with Data 1, Data 2, and Data 3.

\section{Data 1 :}

Situation : You have a friend, he asks you to accompany him to the bookstore this weekend. What do you say to refuse him?

Refusal : Sorry, I am busy. I'm want do house work

The subject answer "Sorry, I am busy. I'm want do house work." as the response to refuse the situation 1, to refuse her friend's ask to accompany her to the bookstore. Her response was classified as indirect refusal with the order of semantic formula was regret + reason. Data 1 showed that the subjects refused the request by saying it indirectly. The indirectness was shown by saying I am busy without directly saying no in her answer then it is followed by the reasons of the subject's answer. Based on this theory, data 1 is classified as indirect refusal.

\section{Data 2}

Situation : You have a friend, he asks you to accompany him to the bookstore this weekend. What do you say to refuse him?

Refusal : Sorry, I am no have money (brother)

The subject answer "Sorry, I am no have money (brother)" as the response to refuse the situation 1, to refuse her friend's ask to accompany her to the bookstore. Her response was classified as direct refusal with the order of semantic formula was regret + non-performative statement.

Data 3

Situation : You have a friend, he asks you to accompany him to the bookstore this weekend. What do you say to refuse him?

Refusal : Sorry, I no want go. Because I want to Zoo.
The subject answer "I'm sorry. I'm no want go because I want to zoo as the response to refuse the situation 1, to refuse her friend's ask to accompany him to the bookstore Her response was classified as direct refusal with the order of semantic formula was regret + non-performative statement + reasons .

\subsubsection{Realization of Politeness in Refusal by the Free Variation Interlanguage Stage Subjects}

The subjects with the free variation stage realized politeness in refusal in five ways, they are (1) indirect refusal by saying regret + reasons, (2) direct refusal by expressing acceptance of refusal + non-performative statement, (3) indirect refusal by expressing regret + reason + future acceptance, (4) direct refusal by expressing regret + non-performative statement + reasons (5) direct refusal by expressing regret + nonperformative statement + future acceptance. Each of these ways is supported by data 4,5,6,7 and 8 .

Data 4

Situation : You have a friend, he asks you to accompany him to the bookstore this weekend. What do you say to refuse him?

Refusal : I'm sorry. I am really lazy.

The subject answer "I'm sorry. I'm really lazy" as the response to refuse the situation 1, to refuse her friend's ask to accompany him to the bookstore. Her response was classified as indirect refusal with the order of semantic formula was regret + reasons.

Data 5

Situation : You have a friend, he is Malay. He said that his parents were late to transfer his money while he needed it right now. He asked you to borrow yours. What do you say to refuse him?

Refusal : I'd like to but I can't.

The subject answer "I'd like to but I can't" as the response to refuse the situation 2 , to refuse her friend's ask to lend her money. Her response was classified as indirect refusal with the order of semantic formula was acceptance as refusal+ non-performative statement. Data 5 showed that the subjects refused the request by saying it directly. The directness was shown by indirect utterance of $I$ can't, that classified as the direct refusal in her answer. The subject said her acceptance as refusal then followed by inability.

Data 6

Situation : You have a friend, he you to accompany him to the bookstore this weekend. What do you say to refuse him? 
Refusal : Sorry. I want to library to read. Next time.

The subject answer "Sorry. I want to library to read. Next time" as the response to refuse the situation 1, to refuse her friend's ask to accompany her to the bookstore. Her response was classified as indirect refusal with the order of semantic formula was regret + reason + future acceptance. Data 6 showed that the subjects refused the request by saying it indirectly. The indirectness was shown by indirect utterance of I want to library to read, that classified as the indirect refusal in her answer. The subject said her regret then followed by reasons and future acceptance.

\section{Data 7}

Situation : You have a friend, he asks you to accompany him to the bookstore this weekend. What do you say to refuse him?

Refusal : I'm sorry, I cannot because I have don't money.

The subject answer "I'm sorry, I cannot because I have don't money" as the response to refuse the situation 1, to refuse her friend's ask to accompany him to the bookstore .His response was classified as direct refusal with the order of semantic formula regret + nonperformative statement + reasons. Data 7 showed that the subjects refused the request by saying directly. The directness was shown by direct utterance of "I cannot" that classified as the direct refusal in his answer. The subject said his regret before his inability. Expression "I cannot" is classified as direct refusal because Beebe et.al (1990) states that direct refusal is characterized with directly saying of no, I can't, I don't want or I refuse, etc.

Data 8

Situation : You have a friend, he is Malay. He said that his parents were late to transfer his money while he needed it right now. He asked you to borrow yours. What do you say to refuse him?

Refusal : I'm sorry. I have don't money. Next time may be.

The subject answer "I'm sorry, I have don't money. Next time may be" as the response to refuse the situation 2 , to refuse her friend's ask to lend him money. His response was classified as direct refusal with the order of semantic formula regret + non-performative statement + future acceptance. Data 8 showed that the subjects refused the request by saying directly. The directness was shown by direct utterance of "I have don't money" that classified as the direct refusal in his answer. The subject said his regret before his inability.

\subsection{The Realization of Politeness in Refusal based on the Subjects' Culture}

The politeness in refusal was realized differently depending on the subjects' culture. There are two different culture involved in this study, namely Malay and Batak culture.

\subsubsection{The Realization of Politeness in Refusal by Malay Culture}

The subjects use five ways of realizing refusal. The five ways are (1) direct refusal by expressing regret + non-performative statement + reason (2) indirect refusal by expressing regret + reason (3) direct refusal by expressing acceptance as refusal + non-performative statement (4) indirect refusal by expressing regret + reason + future acceptance (5) direct refusal by expressing regret + non-performative statement. Each of these ways is presented in details as follows in data 9 , $10,11,12$, and 13 .

Data 9

Situation : You have a friend, he said that his parents were late to transfer his money while he needed it right now. He asked you to borrow yours. What do you say to refuse him?

Refusal : Sorry. I can’t lend money because I neet money.

The subject answer "Sorry. I can't lend money because I neet money." as the response to refuse the situation, to refuse her friend's ask to lend money. Her response was classified as direct refusal with the order of semantic formula was regret + non performative statement + reasons. Data 9 showed that the subjects refused the request by saying it directly. The directness was shown by indirect utterance of can't, that classified as the direct refusal in her answer then it is followed by her reason.

Data 10

Situation : You have a friend, he said that his parents were late to transfer his money while he needed it right now. He asked you to borrow yours. What do you say to refuse him?

Refusal : Sorry, my mother too were late transfer the money.

The subject answer "Sorry, my mother too were late transfer the money" as the response to refuse the situation, to refuse her friend's ask to lend her friend money. Her response was classified as indirect refusal with the order of semantic formula was regret + reasons Data 10 showed that the subjects refused the request by saying it indirectly. The indirectness was shown by indirect utterance of "my mother too were late transfer the money", that classified as the indirect refusal in her 
answer. The subject said her regret then followed by her reason

\section{Data 11}

Situation : You have a friend, he said that his parents were late to transfer his money while he needed it right now. He asked you to borrow yours. What do you say to refuse him?

\section{Refusal : I'd like to but I can't.}

The subject answer "I'd like to but I can't" as the response to refuse the situation 2 , to refuse her friend's ask to lend her money. Her response was classified as indirect refusal with the order of semantic formula was acceptance as refusal+ non-performative statement. Data 11 showed that the subjects refused the request by saying it directly. The directness was shown by indirect utterance of I don't, that classified as the direct refusal in her answer. The subject said her acceptance as refusal then followed by inability.

\section{Data 12}

Situation : You have a friend, he asks you to accompany him to the bookstore this weekend. What do you say to refuse him?

Refusal : Sorry. I want to library to read. Next time.

The subject answer "Sorry. I want to library to read. Next time" as the response to refuse the situation 1, to refuse her friend's ask to accompany her to the bookstore .Her response was classified as indirect refusal with the order of semantic formula was regret + reason + future acceptance.

Data 12 showed that the subjects refused the request by saying it indirectly. The indirectness was shown by indirect utterance of I want to library to read, that classified as the indirect refusal in her answer. The subject said her regret then followed by reasons and future acceptance.

Data 13

Situation : You have a friend, he asks you to accompany him to the bookstore this weekend. What do you say to refuse him?

\section{Refusal : I'm sorry I have no money}

The subject answer "I'm sorry I have no money" as the response to refuse the situation 1 , to refuse his friend's ask to accompany her to the bookstore His response was classified as direct refusal with the order of semantic formula was non performative statement + regret. Data 13 showed that the subjects refused the request by saying it directly. The directness was shown by direct utterance of I have no money, in his answer then it is followed by regret.

\subsubsection{The Realization of Politeness in Refusal by Batak Culture}

The subjects use three ways of realizing refusal. The three ways are (1) direct refusal by non-performative statement+regret, (2) direct refusal by regret + nonperformative statement + reasons and (3) direct refusal by expressing regret + non-performative statement + future acceptance. Each of these ways is presented in details in data 14,15 , and 16 .

Data 14

Situation : You have a friend, he said that his parents were late to transfer his money while he needed it right now. He asked you to borrow yours. What do you say to refuse him?

Refusal : Sorry, I have no money

The subject answer "sorry, I have no money" as the response to refuse the situation 2, to refuse his friend's ask to accompany her to the bookstore. His response was classified as direct refusal with the order of semantic formula was Regret + non performative statement. Data 14 showed that the subjects refused the request by saying it directly. The directness was shown by direct utterance of I have no money, in his answer then it is followed by regret.

\section{Data 15}

Situation : You have a friend, he said that his parents were late to transfer his money while he needed it right now. He asked you to borrow yours. What do you say to refuse him?

Refusal : I'm sorry. I cannot help you because I shall to go my village and I need a money to fare.

The subject answer 'I'm sorry.I cannot help you because I shall to go my village and I need a money to fare" as the response to refuse the situation 2, to refuse her friend's ask to lend her money. Her response was classified as direct refusal with the order of semantic formula regret + non-performative statement + reason Data 15 showed that the subjects refused the request by saying it directly. The directness was shown by direct utterance of "I can't help" that classified as the direct refusal in her answer.

Data 16

Situation : You have a friend, he said that his parents were late to transfer his money while he needed it right now. He asked you to borrow yours. What do you say to refuse him?

Refusal : I'm sorry. I have don't money. Next time may be. 
The subject answer "I'm sorry. I have don't money. Next time may be I give to you" as the response to refuse the situation 2, to refuse her friend's ask to lend him money. His response was classified as direct refusal with the order of semantic formula regret + nonperformative statement + future acceptance. Data 16 showed that the subjects refused the request by saying directly. The directness was shown by direct utterance of "have don't money" that classified as the direct refusal in her answer. The subject said her regret before his inability then followed future acceptance.

Based on the data analysis, it is found that the politeness in refusal among the Batak and Malay culture are both realized by direct and indirect strategy. The strategies used in both culture are followed by semantic formula, such as non performative statement, regret, reason, acceptane as refusal and future acceptance. The difference between the two realizations of politeness in refusal is that the direct strategies are used more in Batak culture than those used in Malay culture. Semantic formula are used less in Batak culture than those in Malay culture.

These findings are supported by the following researches ; Amiruddin \& Saleh (2016) state that Malay tends to use indirect strategies to lessen the facethreatening effect of refusal. These findings also agreed with Sianturi (2015) that states that directness is the dominantly used by Bataknese because they do not like talk long-winded. In addition, the finding also supported Boangmanalu and Lumbangaol (2016) that explains the politeness principle in Bataknese represented in using the word sorry (santabi, marpanganju, and marpamuati). It means that, although Batakanese used direct strategies do not mean that Bataknese do not use politeness principle in their communication especially in refusals. In relation to the cultural and interlanguage effect on politeness, this study are supported Tabatabei (2019) that states the differences of language proficiency contributes on the length of the refusal produced. In this study, the staged-1 subjects tend to use shorter refusal expressions and less semantic formula.

\section{CONCLUSION}

The politeness in refusal among the Batak and Malay culture are both realized by direct and indirect strategies. The difference between the two realizations of politeness in refusal is that the direct strategies are used more in Batak culture than those used in Malay culture.

\section{REFERENCES}

[1] Brown, P. \& S. C., Levinson. 1987. Politeness: Some Universals in Language Usage. Cambridge: Cambridge University Press.

[2] Tarone, E. 2001. Interlanguage. In R. Mesthrie (Eds.), Concise encyclopedia of sociolinguistics (pp. 475- 81). Oxford: Elsevier.
[3] Lakoff, R. 1990. Talking Power: The Politics of Language in Our Lives. Glassgow: Harper Collins.

[4] Song, S. 2012. Politeness and Culture in Second Language Acquisition. London : Palgrave Milan.

[5] Watts, R. 2003.Politeness;Key Topic in Sosiolinguistic. New York : Cambridge University Press.

[6] Fukushima,S. 2003. Requests and Culture: Politeness in British English and Japanese (3rd edition).Berlin : Peter Lang.

[7] Blum-Kulka, S. 1992. The Metapragmatics of Politeness In Israeli Society. In Watts, R., Ide, S. \& Ehlich, K. (Eds.), Politeness in Language: Studies In Its History, Theory and Practice (pp. 255-280). Berlin: Mouton de Gruyter.

[8] Beebe, L., Takahashi, T and R. Uliss-Weltz, 1990.Pragmatic Transfer in ESL Refusals. In Scarcella, R. C., Anderson, E. \& Krashen, S. C. (Eds.), Developing Communicative Competence in a Second Language (pp. 55-73). New York: Newbury House.

[9] Sianturi,S. 2015.The Realization of Politeness Strategies Used by The Toba Batak Teenagers in Lintongnihuta. Methoda Vol 5 No 2

[10]Rahman, A. N. J., \& M. Yusof,.2017. Strategi Berkomunikasi Generasi Muda Melayu: Analisis Lakuan Bahasa Penolakan. Jurnal Melayu

[11] Selinker, L. 1972. Interlanguage.IRAL; International Review of Applied Linguistics in Language Teaching, 10:3 (1972) p.209

[12]Ellis, R. 1987. Interlanguage Variability in Narrative Discourse: Style Shifting in the Use of the Past Tense. Studies in Second Language Acquisition, 9, 1-20

[13] Roever, C. 2011. Testing of Second Language Pragmatics: Past and future.Language Testing, 28(4), 463-481.

[14] Wang, Q. 2019. A Comparative Study of Gender Differences in Refusal Strategies from English Majors. Theory and Practice in Language Studies, Vol. 9, No. 8, pp. 1040-1048

[15]Miles et al. 2014. Qualitative Data Analysis: A Methods Sourcebook. Third edition. SAGE Publications 